
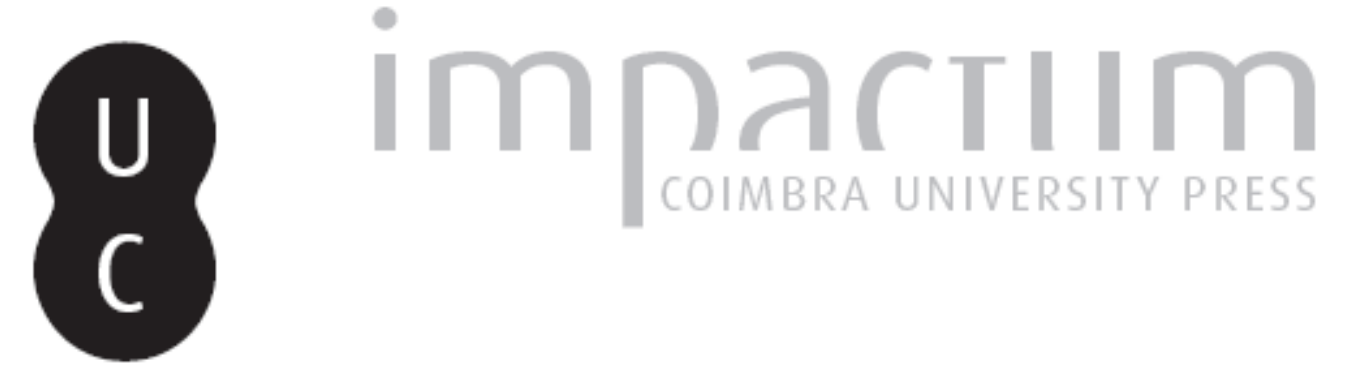

La primera partición de los bienes de Don Diego Pérez Sarmiento II, Conde de Santa
Marta, y la concesión del título de Conde de Ribadavia (1476)

Autor(es): $\quad$ Fernández Suárez, Gonzalo Francisco

$\begin{array}{ll}\text { Publicado por: } & \text { Instituto de História Económica e Social; Imprensa da Universidade de } \\ \text { Coimbra }\end{array}$

URL

persistente:

DOI: $\quad$ DOI:https://doi.org/10.14195/0870-4147_37_16

Accessed : $\quad$ 26-Apr-2023 11:57:46

A navegação consulta e descarregamento dos títulos inseridos nas Bibliotecas Digitais UC Digitalis, UC Pombalina e UC Impactum, pressupõem a aceitação plena e sem reservas dos Termos e Condições de Uso destas Bibliotecas Digitais, disponíveis em https://digitalis.uc.pt/pt-pt/termos.

Conforme exposto nos referidos Termos e Condições de Uso, o descarregamento de títulos de acesso restrito requer uma licença válida de autorização devendo o utilizador aceder ao(s) documento(s) a partir de um endereço de IP da instituição detentora da supramencionada licença.

Ao utilizador é apenas permitido o descarregamento para uso pessoal, pelo que o emprego do(s) título(s) descarregado(s) para outro fim, designadamente comercial, carece de autorização do respetivo autor ou editor da obra.

Na medida em que todas as obras da UC Digitalis se encontram protegidas pelo Código do Direito de Autor e Direitos Conexos e demais legislação aplicável, toda a cópia, parcial ou total, deste documento, nos casos em que é legalmente admitida, deverá conter ou fazer-se acompanhar por este aviso.






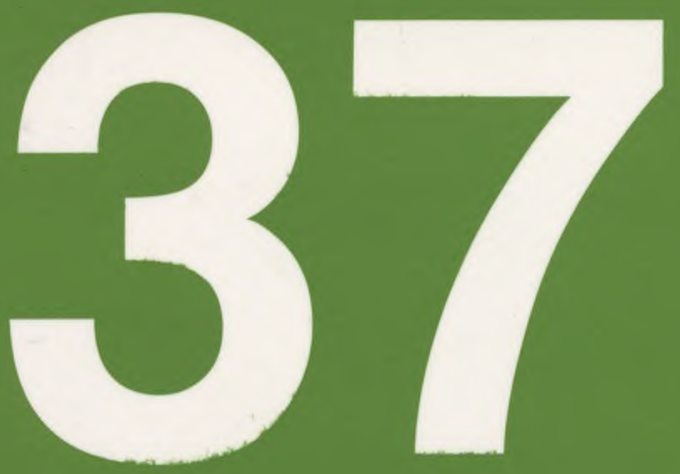

Revista Portuguesa de História

Faculdade de Letras da Universidade de Coimbra Instituto de Historia Econónica e Samial

Coimbra 05 
Revista Portuguesa de Historia

t. XXXVII (2005)

pp. 377-392

\section{La Primera Partición de los Bienes de Don Diego Pérez Sarmiento II, Conde de Santa Marta, y la Concesión del Título de Conde de Ribadavia (1476)}

GONZALO FRANCISCO FERNÁNDEZ SUÁREZ Universidad de Santiago

Hacia mediados del siglo XV, el señorío de Don Diego Pérez Sarmiento, conde de Santa Marta de Ortigueira y Adelantado Mayor de Galicia ${ }^{1}$, había alcanzado unas dimensiones considerables. Tres eran los factores que habían determinado este crecimiento: la política de donaciones desplegada por la monarquía a favor de sus antecesores, en especial a su abuelo Don Pedro Ruiz Sarmiento², Adelantado Mayor de Galicia; las donaciones realizadas por particulares y, finalmente, las adquisiciones efectuadas a diversas personas y entidades. Junto a la villa de Santa Marta de Ortigueira a la que aparecía adscrito su título condal, el actual titular acumulaba un basto patrimonio que incluía, entre otras, las villas de Ribadavia, Salvaterra, las tierras de Avión, Orcellón, Sobroso, Montes, Castro Caldelas, Ribas de Miño, cotos como el de Añilo y diversas feligresías en A Limia. El mismo panorama podía pintarse en Castilla. A la villa de Mucientes se habían unido en fecha desconocida las de Fuentes de Valdepero, Palazuelos de Vedija

1 La trayectoria vital de este personaje aparece recogida por FERNÁNDEZ SUÁREZ, GONZALO FRANCISCO: La nobleza gallega entre los siglos XIV-XV: los Sarmiento, condes de Ribadavia. Santiago de Compostela, 2002, pp. 135-191.

2 Idem, pp. 86-95. 
y Tariego. Además, percibía una serie de sumas nada despreciables en concepto de juros situados en Frechilla, Palencia o en la misma Fuentes de Valdepero. Sin embargo, a estas alturas de su vida el conde de Santa Marta aún no había logrado asegurar la sucesión de su casa con un hijo varón que honrase su nombre y estirpe. Nos consta, por testimonios posteriores, que el matrimonio formado por Don Diego y su esposa, Doña Teresa de Zúñiga, sólo había conseguido engendrar una hija llamada Teresa ${ }^{3}$, muerta, al parecer, en edad pueril dadas las nulas noticias que hemos hallado sobre ella en vida de sus padres. Con cierta tristeza y resignación nuestro personaje reconocía a la altura de 1453 que “... yo non tengo fijos legitymos de la Condesa, mi legityma muger, ...". Ante tan delicada situación al señor conde no le quedó más remedio que recurrir a un vástago suyo, fruto de sus relaciones extraconyugales. Don García Sarmiento, que así se llamaba, había sido legitimado por su padre en fecha que desconocemos. Con todo, esta debió ser anterior a 1436 cuando tenemos por primera vez constancia documental de su existencia. En esa fecha Don García ya aparecía designado como sucesor. El 24 de marzo de este año Gómez de Bóveda prestaba juramento de pleito homenaje al candidato a conde de Santa Marta por la fortaleza de Formigueiro. Entre otras cosas, se comprometía a acudir con ella a Don García o a su tutor en el caso de fallecer su padre sin sucesión ${ }^{4}$. Queda claro, por lo tanto, que el recurso a este hijo se contemplaba como última solución en el supuesto de que no hubiese descendencia legítima. Descendencia que, como hemos dicho, no llegaría y convertiría a Don García en el heredero del título condal de Santa Marta y todas sus posesiones.

Una vez asegurado el futuro de su casa, Don Diego se planteó la necesidad de conseguir para su hijo un entronque acorde con su status. Con este objetivo, el señor conde escudriñó el mercado matrimonial castellano en la procura de la futura esposa de su hijo. Así, el 8 de diciembre de 1453 llegaba a un acuerdo con su pariente Pedro Sarmiento, Repostero Mayor del Rey, para el desposorio de sus hijos, dejando bien claro de entrada la condición de Don García como heredero universal de todo su patrimonio:

"Sepan quantos esta carta vieren, como yo Don Diego Peres Sarmiento, Conde de Santa Marta, por quanto entre vos el señor Pedro Sarmiento, Repostero Mayor del Rey, nuestro señor, e entre mi es conçertado de casar

\footnotetext{
3 A ella alude Don Bemardino Pérez Sarmiento, conde de Ribadavia, en 1493 en su testamento al enumerar las tumbas existentes en el interior de la iglesia de San Pedro de Mucientes. Documento publicado por FERNÁNDEZ SUÁREZ, GONZALO FRANCISCO: La nobleza gallega .... op. cit., pp. 537-549.

4 PARDO DE GUEVARA Y VALDÉS, EDUARDO JOSÉ: Los linajes de la nobleza gallega en el tránsito de la Edad Media a la Moderna (1300-1600). Carpeta Sarmiento, inédito.
} 
nuestros fijos, es a saber, Don Gargia Sarmiento, mi fijo mayor legitymado, a quien pertenesge aver e heredar mi casa e mayoradgo e bienes con Doña Mengia Sarmiento, vuestra fija, segund se contiene en giertos apuntamientos que oy dia fesimos e firmamos de nuestros nonbres".

Sin embargo, en los acuerdos que ambos proceres otorgaban a continuación puede observarse una cierta precaución contra la más que probable existencia de otros hijos ilegítimos y los problemas que esto podía acarrear. Veamos:

- La dote entregada a Doña Mencía por su padre ascendería a 10.000 florines de oro.

- Por su parte, Don Diego prometía pagarle 5.000 florines de oro en concepto de arras en el plazo de un año.

- Las arras se pagarían en metálico o en otros bienes de valor equiparable.

- El señor conde ponía como garantía sus bienes.

- Se autorizaba a Doña Mencía a ocupar los bienes de su suegro mientras no se le pagasen las arras y gozar de su rentas.

- Podría apropiarse de los bienes que deseara sin guardar ningún tipo de orden.

- Se declaraba a Don García heredero legítimo.

- Su padre prometía no legitimar a otros hijos.

- Incluso aunque reconociese a otros hijos, Don García seguiría siendo su sucesor.

- Se facultaba a Don García y a sus hijos para que tomasen posesión del condado de Santa Marta tras la muerte de su actual titular.

- Para mayor seguridad Don Diego prestaba solemne juramento de pleito homenaje en manos de Don Pedro Sarmiento ${ }^{5}$.

Poco tiempo estuvo vigente esta escritura. Tan sólo seis días después, Don Diego y Don Pedro redactaban un nuevo documento. En su conjunto mantenía la mayoría de las cláusulas anteriores, pero añadía una serie de cambios en las condiciones iniciales:

- El pago de las arras se realizaría en oro o en plata.

- Doña Mencía podrá vender los bienes que ocupase mientras éstas no se le pagasen.

- También podrá tomar todos los bienes que considere necesarios para su cobro y para resarcirse de las costas que esto le ocasionara.

- Don Diego entregaría a su hijo en el momento de casarse los lugares de Valverde, Castril de Onierlo y Terrados cuya enagenación queda totalmente prohibida.

- Ambas partes se comprometen a pedir dispensa papal por razón del parentesco en cuarto grado de los futuros cónyuges.

s Documento publicado por FERNÁNDEZ SUÁREZ, GONZALO FRANCISCO: La nobleza gallega op. citpp. 394-400. 
- No se alude para nada a la posibilidad o no de legitimar a otros hijos.

- Quedan anuladas todas las escrituras anteriores que sobre este asunto se hubieran otorgado ${ }^{6}$.

Un hecho vino a trastocar estos planes pocos años después. Al parecer, la fama de mujeriego que perseguía al señor conde de Santa Marta contaba con sólidos argumentos. Principalmente, entre sus esclavas domésticas quienes podían atestiguarlo con absoluta certeza. Una de ellas llamada Úrsula daría a su amo un nuevo hijo al que éste bautizó con el nombre de Bemardino. Poco después, Don Diego elevaba una súplica a la Corona con vistas a legitimarle. A su favor alegaba el hecho de que no había tenido hijos en su matrimonio con Doña Teresa:

"Por quanto por parte de vos Don Diego Peres Sarmiento, Conde de Santa Marta, mi Adelantado Mayor del Reygno de Galisia e del mi Consejo, me fiie fecha relaçion que vos el dicho Conde seyendo casado, segund ordenamiento de la Santa Madre Eglesia, con Doña Theresa de Estuñiga, Condesa de Santa Marta, vuestra legityma muger, ovistes a Don Bemaldo, vuestro fijo, en Ursula, su madre, seyendo ella esclava vuestra e de la dicha Condesa, vuestra muger, seyendo ella moça soltera e non seyendo ella obligada a otro matrimonio ni desposorio alguno. $E$ me fue pedido por merçed por vuestra parte que, por quanto vos non teniades fijos algunos legitymos de legitymo matrimonio nasçidos, que legitymase e abilitase $<e>$ fise legitymo e abile e capas al dicho Don Bemaldo, vuestro fijo, ..."

Casi al mismo instante Enrique IV aceptaba los argumentos de Don Diego y extendía la consiguiente escritura de legitimación, ratificando a Don Bemardino en su nueva condición aunque su padre tuviese de antemano otros hijos legitimados?. Esta acción en si equivalía a una ruptura con lo acordado anteriormente y daría lugar con el paso de los años a un progresivo apartamiento de Don García de la línea sucesoria y su sustitución por su hermano. Hecho este que era evidente a comienzos de 1465 cuando por iniciativa expresa del conde de Santa Marta, Enrique IV confirmaba a Don Bemardino el título de Adelantado Mayor de Galicia. A continuación el monarca hacía un llamamiento a todas las ciudades y villas gallegas para que acudiesen a Don Bemardino con todos los derechos y rentas

6 Escritura de dote y arras fechada en Mucientes el 14 de Diciembre de 1453. Arquivo Histórico Universitario de Santiago, Fondo Medinaceli, Sección Ribadavia, Microfilm 304 legajo 4 número 10 (Desde ahora para citar este archivo nos atendremos, tomando este documento como ejemplo, a las siguientes siglas: A.H.U.S., Medinaceli, Ribadavia, M. 304 leg. 4 n. $\left.{ }^{\circ} 10\right)$.

7 Escritura de legitimación publicada por FERNÁNDEZ SUÁREZ, GONZALO FRANCISCO: La nobleza gallega ..., op. cit., pp. 420-424. 
inherentes a este caigo. Dada su minoría se le facultaba para ser habido por mayor de edad ${ }^{8}$. El objeto de este traspaso sólo puede comprenderse si atendemos al significado que este cargo tenía para los Sarmiento. Antes de que Don Diego Pérez Sarmiento II alcanzase la dignidad condal, el título por el que se había identificado todos sus antecesores era el de Adelantado Mayor de Galicia. $\mathrm{Su}$ patrimonialización en este linaje lo había transformado en una propiedad más que se transmitía de heredero en heredero. Del mismo modo, su disfrute llevaba aparejado la percepción de una serie de rentas. Con esta cesión Don Diego trataba de proporcionar a su hijo un caudal suficiente con el que mantenerse a la espera de sucederle en la jefatura de su casa. Sucesión de la que Don García se encontraba excluido en este momento: en el supuesto de fallecer Don Bemardino, el Adelantamiento de Galicia retomaría a manos de su padre. Los mismos alcaides de las fortalezas demostraban estar al corriente del cambio de decisión de su señoría. Cuando en 1464 Femando de Camba y Fernán García Mosquera rendían pleito homenaje por la fortaleza de Castro Caldeias, prometían, en el caso de que falleciesen Don Diego y Doña Teresa, su esposa, acudir con esta fortaleza a Don Bemardino9 ${ }^{\text {. }}$

La confirmación definitiva de Don Bemardino como sucesor al frente de la casa de Santa Marta se produciría en el momento de dictar su padre sus últimas voluntades. También en su testamento Don Diego explicaba las razones que habían influido en su cambio de parecer respecto a Don García. Según él mismo refería, se sentía disgustado con el comportamiento rebelde de este hijo, pese a lo cual siempre le había conservado un gran afecto:

"Otrosy por quanto yo ove un hijo que se llamava Don Garçia, hera bastardo, pero hera legitimado por el señor Rey para que con mi mandado el pudiese heredar la parte de mis bienes que yo le dexase, el qual file casado con Doña Mençia, fija de Pedro Sarmiento que fue despues Conde de Salinas. Y porque el dicho Don Garçia despues que fue onbresillo nunca estovo a mi mandado e obediençia, yo me tove syenpre asentado en mi coraçon de voluntad de non le aver por mi fijo para que el heredase mi casa e bienes ..."

Lo único que le dejaba era una especie de legítima corta integrada por los bienes que se había comprometido a entregarle el día de su desposorio, esto es, Valverde, unos vasallos en Valcañas y Terrados, la heredad y casa de Castrillo y la heredad

\footnotetext{
${ }^{8}$ Carta de privilegio y confirmación dada en Olmedo el 8 de Enero de 1465.A.H.U.S.,Medinaceli, Ribadavia, M. 303 leg. 1 n. ${ }^{\circ} 57$.

' Documento publicado por FERNÁNDEZ SUÁREZ, GONZALO FRANCISCO: La nobleza gallega ...,op. cit., pp. 424-429.
} 
que poseía en Valcañas de Suso. Al igual que a su nieto Don Francisco, hijo de Don García, a quien cedía las propiedades que poseía en Cerrato, mientras que para cada una de sus tres hermanas que se criaban en su casa disponía la entrega de 300.000 maravedíes para sus casamientos. Como salvaguarda de todo lo anterior, anulaba todos los testamentos y escrituras ante la insistencia de su nuera "... porque dise la dicha Doña Mençia que tiene recabdos fuertes los quales ella non puede mostrar sy falsos non fueren Pero quizás Doña Mencía y sus hijos ya hubieran comenzado a inquietar al moribundo conde porque éste se ratificaba en su decisión afirmando que "... aquello apruevo e mando que se cunpla e non mas" 1011.

Tal y como había pronosticado en su día Don Diego Pérez Sarmiento, los descendientes de Don García no aceptaron de buen grado la decisión convertir a Don Bemardino en su heredero universal. Una primera prueba de todo ello se produjo durante la revuelta irmandiña de 1467-1469. Según declaraba años después Gonzalo Durán, Doña Mencía Sarmiento, viuda de Don García, se había apoderado con el apoyo de los irmandiños de la villa de Ribadavia en cuya posesión había estado cuatro o cinco años. Más tarde, Doña Teresa de Zúñiga, esposa del difunto conde de Santa Marta y tutora de Don Bemardino, la había expulsado gracias a la ayuda de Pedro Álvarez de Soutomaior:

\footnotetext{
“...la vio thener a la dicha doña Mencia (Sarmiento)... por tiempo de quatro o cinco años fasta que un Pero Alvarez de Sotomayor tubo trabto coon la dicha doña Mencia e entro en la dicha villa por traycion e la prendió e hecho fuera de la dicha villa de Rrybadavia e al dicho su hijo e hermano e envio por la dicha condesa (de Santa Marta) doña Teresa e la tomo a entregar en la dicha villa.. ." n
}

Este primer fracaso no hizo desistir a Doña Mencía en su empeño de ver reconocidos los derechos de su hijo Francisco. Desde entonces sus reclamaciones sobre el patrimonio del nuevo conde de Santa Marta no hicieron sino incrementarse. Ante ello a Don Bemardino sólo le cabía apelar a las cláusulas testamentarias de su padre, sin que por ello consiguiese acallar las constantes demandas. Tanto era así, que hacia mediados de la década de los años 70 del sigloXV este asunto había llegado a un punto de inflexión en el que sólo cabía una solución: un arreglo amistoso entre las partes implicadas. Doña Mencía

${ }^{10}$ Idem, pp. 429-435.

11 COOPER, EDWARD: Castillos señoriales en la Corona de Castilla y León. Valladolid, $1991,1.2$, p. 807. 
parecía adivinar que este momento se hallaba cercano, cuando en marzo de 1476 Juan Alfonso de Toro, alcalde real, se disponía a nombrar un juez árbitro que mediase entre las partes. Esta responsabilidad recaería por expreso deseo de los interesados en la persona de Don Diego Gómez Sarmiento, conde de Salinas y hermano de Doña Mencía ${ }^{12}$. Dos días después, el 11 de marzo de 1476, Don Bemardino y Don Francisco firmaban una concordia. Con este gesto tío y sobrino trataban de poner fin a las agrias disputas que mantenían por la herencia de Don Diego Pérez Sarmiento y a la que cada uno, según decían, afirmaba tener derecho. El convenio al que llegaron ambos personajes puede resumirse en los siguientes puntos:

- Entrega a Don Francisco de las villas de Santa Marta de Ortigueira y Palazuelos de Vedija junto con todas sus propiedades y rentas. Tras conseguir licencia real podrá intitularse conde de Santa Marta.

- Por su parte, Don Bemardino quedaba en posesión del Adelantamiento Mayor de Galicia, las villas de Ribadavia, Fuentes, Mucientes, coto y fortaleza de Celmes, Laza y Bentraces, los maravedíes de juro que poseía en Frechilla y Palencia, todos los demás juros de merced de por vida y todos los bienes muebles, raíces y semovientes que habían quedado de los difuntos condes.

- Renuncia mutua del derecho a los bienes asignados a cada una de las partes y licencia para que cada uno pueda tomar posesión.

- Si alguno de ellos fallece sin descendencia, sus bienes pasarán al otro. En el caso de Don Francisco, la mitad de éstos quedarán para sus hermanas o su herederos.

- Cada uno de ellos podrá disponer de hasta 1.500.000 de maravedíes para descargos y obras pías.

- Promesa de no plantear ninguna reclamación futura por razón de este compromiso. Si alguno contradice esta decisión, pagará al otro 3.000 castellanos de oro del cuño del rey de Castilla.

- En el supuesto de que Don Francisco reclame más bienes, perderá todos los asignados y todo el derecho que a ellos tiene.

- Solemne juramento de acatar todo lo establecido ${ }^{13}$.

12 Carta de nombramiento publicada por FERNÁNDEZ SUÁREZ, GONZALO FRANCISCO: La nobleza gallega ..., op. cit., pp. 461-470.

${ }^{13}$ Concordia publicada por FERNÁNDEZ SUÁREZ, GONZALO FRANCISCO: La nobleza gallega ..., op. cit., pp. 470-482. 


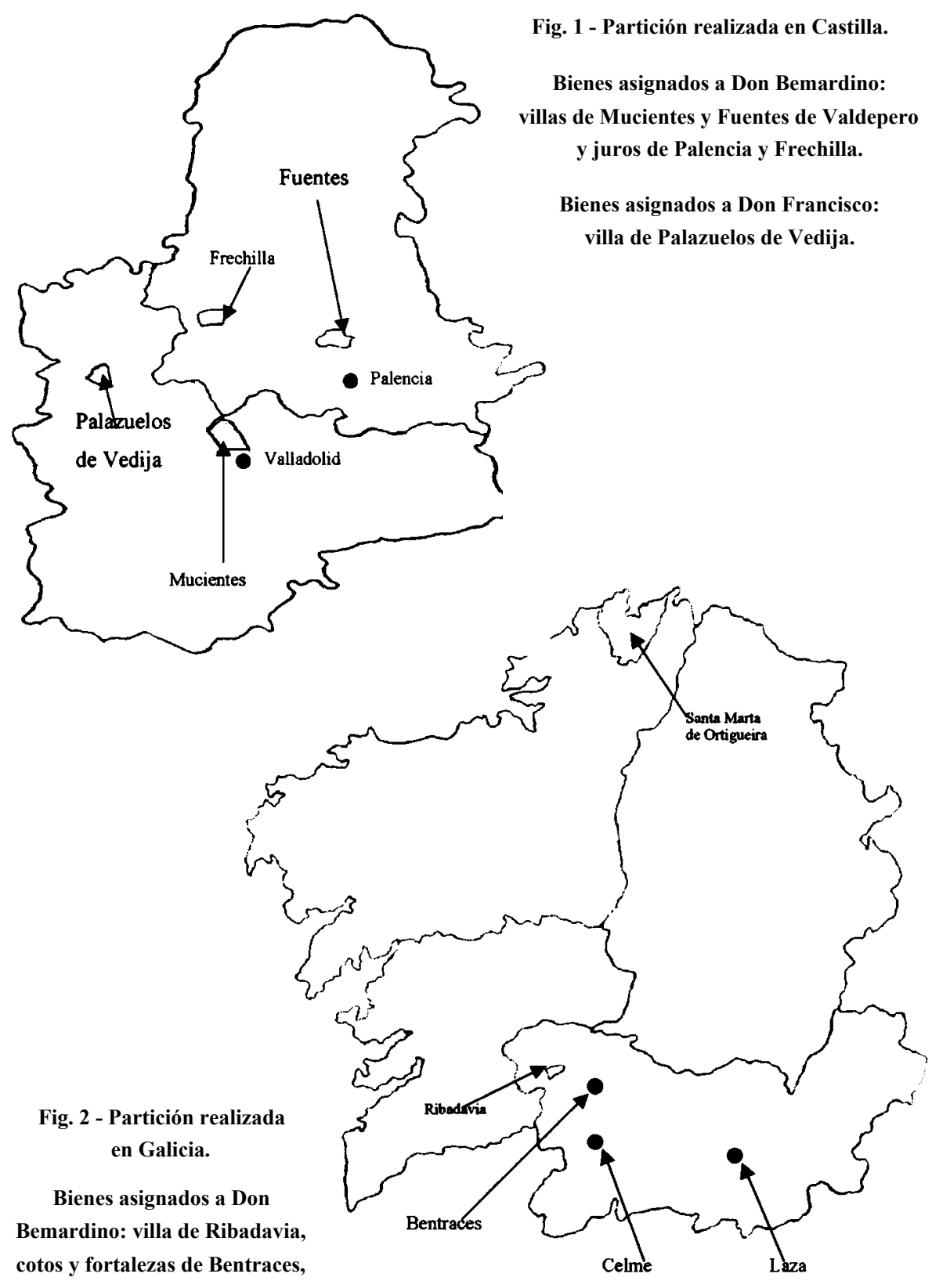

Celme y Laza.

Bienes asignados a

Don Francisco: villa de

Santa Marta de Ortigueira. 
No sólo Don Bemardino mantenía diferencias con su sobrino Don Francisco. A su lado se situaron su madre Doña Mencía y sus hermanas Doña Teresa, Doña Constanza y Doña María Sarmiento. Pero éstas, lejos de proseguir con la demanda, se daban por satisfechas con el arreglo al que se había llegado y declinaban plantear cualquier reclamación en el futuro. Los motivos que las impulsaban a ello eran tres: primero, su hermano quedaba encargado de dotarlas convenientemente, además su tío Don Bemardino les había entregado una serie de bienes de gran valor para sus casamientos y, finalmente, el deseo de que reinase la paz y la armonía en su familia. Con estas palabras lo expresaban las interesadas:

“... nuestra yntençion e voluntad es de conplir e mantener aquello que asi fue tratado e prometimos de faser porque al dicho señor conde Don Françisco, nuestro hermano, queda el cargo de nos dotar e alimentar e aun porque allende desto e aun de las dichas villas de Santa Marta e de Palaçuelo, el dicho conde Don Bemaldino, nuestro tio, nos ha dado e da e entrega otras heredades e bienes e cosas de grand valor e quantia para ayuda de los dichos nuestros casamientos de su propia voluntad, syn condiçion nin nesçesidad alguna, de que nosotras somos bien contentas e pagadas, e porque entre los dichos Condes e entre nuestros parientes e señores e amigos e valedores aya e sea conservada toda pas e concordia e çesen los males e guerras e peligros que deste fecho e por cabsa del estavan aparejados ..."

A continuación renunciaban a cualquier derecho que les pudiera quedar sobre estos bienes y prometían no contradecir esta renuncia que otorgaban. Para mayor seguridad prestaban juramento ${ }^{14}$.

Un mes después en abril de 1476, los Reyes Católicos daban fe de los litigios que recientemente se habían sucedido entre el conde Don Bemardino y su sobrino Don Francisco. Los monarcas demostraban estar al tanto de todos los pormenores del acuerdo que se había rubricado en Mucientes: el reparto realizado, la renuncia a todo derecho y a plantear nuevas demandas en el futuro, el traspaso de bienes a la parte contraria si uno de ellos fallecía, la cuantía dedicada a obras pías etc. Concluida esta relación procedían, a petición de los interesados, a confirmar todos los capítulos. Únicamente ponían objeción en lo que atañía al Adelantamiento de Galicia y a los maravedíes de merced. En este apartado Isabel y Femando hacían valer su reserva al tratarse de mercedes reales. Si bien confirmaban su título de adelantado de por vida, se mostraban mas reticentes a hacer lo mismo con los juros que "..., queremos que queden e 
Jynquen a nuestra libre dispusyçion. " Don Bemardino aprovechó esta ocasión para solicitar la concesión real de poder intitularse conde de Ribadavia. Según él mismo exponía, dado que, junto con la villa de Ortigueira, su sobrino había llevado aparejado el título condal, era de justicia que él pudiera obtener el de Ribadavia. Petición esta a la que los monarcas respondieron afirmativamente:

"E por quanto vos el dicho conde Don Bemardino fasta aqui fiiystes llamado y intitulado de Conde de Santa Marta e agora por rason de la dicha yguala e (fol.2v.) concordia dexastes la villa de Santa Marta al dicho conde Don Françisco el quai se a de llamar y intitular Conde de Santa Marta e suplicastesnos e pidystesnos por merçed que vos diesedes lugar e liçençia para mudar el dicho tytulo y nonbre para que de aqui adelante vos llamasedes y intitulasedes y podays intitular e llamar Conde de la vuestra villa de Ribadavia. Por ende y por vos faser bien e merçed, por la presente vos la otorgamos y conçedemos asi y vos fasemos Conde de la dicha vuestra villa de Ribadavia y vos llamamos Conde de Ribadavia e Adelantado Mayor del dicho Reyno de Gallisia e queremos que asy seays llamado y nonbrado por todos los de nuestros reynos y fuera dellos, asi por palabra como por escripvanos publicos o privados o en otra qualquier manera".

Como remate, Isabel y Femando advertían que ésta sería la única determinación sobre este pleito ${ }^{15}$.

\section{Apéndice Documental}

1476, Abril, 16 - Madrigal

Provisión real de los Reyes Católicos confirmando el acuerdo al que llegaron Don Bemardino Pérez Sarmiento, conde de Ribadavia, y su sobrino Don Francisco Sarmiento sobre la herencia de Don Diego Pérez Sarmiento, conde de Santa Marta. Incluye una cláusula por la que se autoriza a Don Bemardino poder intitularse conde de Ribadavia.

A.H.U.S., Medinaceli, Ribadavia, M. 302 leg. 1 n. ${ }^{\circ} 33$

(fol. 1) En la noble villa de Valladolid, estando y la corte y chançelleria del Rey e Reyna, nuestros señores, honse dias del(sic) otubre, año del nasçimiento de Nuestro Salvador Ihesuchristo de mili e quatroçientos y setenta e seys años. Ante el bachiller Juan Alonso de Toro, alcalde de los dichos Rey e Reyna, 
nuestro señores, en la dicha su corte e chançelleria, en presençia de mi Graviel de Valladolid, escrivano de camara de los dichos Rey e Reyna, nuestros señores, en la su corte e en todos los sus reynos e otrosy escrivano de la provinçia del reyno de Leon e de la su abdiençia en la dicha su corte e chançelleria, e de los testigos de yuso escriptos, paresçio Ferrand Garçia de Valladolid, escrivano de la dicha abdiençia, procurador en la dicha corte y vesino de la dicha villa de Valladolid, en bos e en onbre del magninfico señor Don Bemardino Sarmiento, Conde de Ribadavia, Adelantado Mayor de Gallisia, e presento ante el dicho bachiller e alcalde una carta de los dichos Rey e Reyna, nuestros señores, fyrmada de sus nonbres e de otros çiertos nonbres e señales, segund que por ella paresçia, escripia en papel, el thenor de la quai es este que sigue:

Don Ferrando y Doña Ysabel, por la graçia de Dios, Rey y Reyna de Castilla, de León, de Toledo, de Çiçilia, de Portugal(sic), de Gallisia, de Sevilla, de Cordova, de Murçia, de Jahen, del Algarbe, de Algesira e de Gibraltar, prinçipes de Aragon e señores de Viscaya y de Molina.

Por quanto nos somos informados que entre el conde Don Bemardino Sarmiento, fijo de Don Diego Peres Sarmiento, Conde de Santa Marta, de la una parte, y el conde Don Françisco Sarmiento, fijo de Don Garçia Sarmiento, defunto, e nieto del dicho Conde Don Diego Peres Sarmiento, de la otra, es fecha $\mathrm{y}$ ha pasado çierta yguala y concordia y pacto e transaçion sobre rason de las questiones e debates que en uno thenian e esperavan los dichos Condes sobre los bienes y fortalesas y villas y lugares y vasallos y oro e plata y joyas y sobre toda la otra herençia e bienes muebles y rayses que fueron e fyncaron del dicho conde Don Diego Peres e de la condesa Doña Theresa de Çufiiga, su muger, a la qual herençia y subçesion amos los dichos condes Don Bemardino y Don Françisco pretendían thener acçion e derechos por virtud de çiertos mayoradgos e testamentos e donaçiones e otras dispusyçiones fechas por los dichos conde Don Diego Peres e condesa Doña Theresa, su muger, por virtud de çiertas facultades e liçençias e otras provisiones que fueron dadas y conçedidas a los dichos Conde e Condesa, defuntos, por los señores rey Don Juan e rey Don Enrrique, nuestros padre y hermano que santa gloria ayan. E paresçe como por la dicha concordia e pacto y transaçion al dicho conde Don Françisco Sarmiento fyncan e quedan las villas de Santa Marta con la peña de Hortiguera y la villa de Palaçuelo de Vedija con sus fortalesas y vasallos e distritos y juridiçion alta e baxa y miro y misto inperio y con todos sus terminos y pechos y derechos y yantares y escrivanias y con las otras sus pertenençias. E copo y fue dexado por la dicha yguala y concordia al dicho conde Don Bemardino el Adelantamiento de Gallisia e las villas de Fuentes y Musientes e de Ribadavia con los cotos de 
Çelme y Ventrases y Laça con todos sus vasallos y fortalesas y juridiçion çevil e creminal e mas todos los otros lugares y aldeas y granjas y heredamientos e otros qualesquier bienes muebles y rayses y pan y vyno y oro y plata y joyas e arreos de casa y esclavos y bestias y ganados e homamientos de capylla y debdas y todos los otros y qualesquier bienes que fyncaron e quedaron del dicho Conde y Condesa de Santa Marta, e todas sus pertenençias y derechos y acçiones y esquelmos y rentas dellos. (fol.lv.) E dieronse por libres e quitos el uno al otro y el otro al otro de todo y qualquier derecho que demas de las dichas partes a ellos contingentes les pertenesçiesen e pudiese pertenesçer, sobre lo qual otorgaron çiertos contratos conjuramento.

E otrosy se contyene en la dicha yguala que fallesçiendo qualquier de los dichos Condes sy fijos o nietos o otros desçendientes ligytymos y de ligitymo $\mathrm{y}$ verdadero matrimonino nasçidos e procreados, que por ese mesmo fecho e derecho se buelvan e tomen todas las dichas villas e lugares e otros bienes que de la susçesion del dicho Cconde Don Diego Peres ovieren e tovieren al tienpo y sason de su fyn e muerte en el que dellos sobrebiviere y quedare bivo y despues de la muerte del otro, con tanto que el dicho conde Don Françisco pueda disponer de la meytad de los dichos bienes que asi fueron del dicho Conde, su ahuelo, e toviere al tienpo de su fyn e muerte y mandarlos a sus hermanas o a sus fijos délias o a qualquier dellos o délias que quisiere.

E otrosy con tanto que cada uno de los dichos Condes pueda y puedan disponer de los dichos bienes y herençia del dicho conde Don Diego Peres que toviere al tienpo de su muerte fasta en un cuento y medio de maravedís para conplir e descargar sus animas y para pagar a sus criados y para otras cosas que quieran e para que de otros qualesquier bienes que tengan y ayan de aqui adelante e ovieren que en la dicha escriptura y contrato que sobre la dicha rason entre ellos paso que ante nos fue mostrada.

E allende desto, nos es fecha relaçion que Doña Mençia Sarmiento, muger del dicho Don Garçia e madre del dicho conde Don Françisco, renunçio todos los derechos e acçiones que thenia e le podian conpeter en qualquier manera a los dichos bienes e herençia y subçesion del dicho Conde por rason de su dote y arras y de la ypoteca y obligaçion que le fue fecha e constituyda sobre çiertas villas y lugares y sobre los otros bienes del dicho Conde de Santa Marta.

E pydieronnos por merçed los dichos Condes e la dicha Doña Mençia que nos aprovasemos y confyrmasemos la dicha yguala y concordia para que fuese fyrme y valedera para agora y para syenpre jamas y interpusiésemos a todo ello nuestra abtoridad y real decreto y los proveyésemos sobre ello como la nuestra merçed fuese. Y nos acatando la calidad y condiçion de los dichos debates y questiones y por los quitar de entre ellos e otrosy aviendo consideraçion a los 
muchos y buenos y contynuos serviçios que los dichos Condes nos han fecho y esperamos que nos faran de aqui adelante e por otras muy justas cabsas que a ello nos mueven de que somos conplidamente çertyficados e porque cunple asi a nuestro serviçio e a la pas y sosiego de nuestros reynos, por esta nuestra carta confyrmamos y ratificamos y aprovamos el dicho pacto y yguala y convenençia asy fecha e otorgada por las dichas partes y por cada una délias, con todas sus clausulas y fyrmesas y fuerças y condiçiones y limitaçiones y juramentos e penas; lo qual todo avernos aqui por repetido asi como si de palabra a palabra aqui fuese expresado. $Y$ queremos y mandamos que la dicha concordia $y$ transaçion dure y permanesca entre las dichas partes y vala y sea fyrme para agora y para syenpre jamas y que todas las dichas partes y sus herederos sean thenidos y obligados de estar e quedar por ella y de no la contradesir en todo nin en parte alguna nin en ningún tienpo nin por ninguna cabsa nin rason nin color que sean de fecho nin de derecho. Y sy lo Asieren o contra ello fueren o vinieren en qualquier manera, mandamos que les non vala nin sean oydos en juysio nin fuera del ellos nin sus herederos nin otro alguno por ellos, e por ese mismo fecho cayan y incurran y ayan caydo y incurrido (fol.2) en las dichas penas y intereses contenidos en los dichos contratos y juramentos, eçeto en lo que toca al Adelantamiento del Reyno de Gallisia e en los maravedís de merçed de por vida que el dicho conde Don Diego Peres Sarmiento tovo en su vida, ca nos aprovamos y confyrmamos el dicho Adelantamiento al dicho conde Don Bemardino para que lo tenga e posea para en toda su vida, segund que lo thenia de merçed para en toda su vida del señor rey Don Enrrique, nuestro hermano cuya anima Dios aya, e los maravedís de por vida que el dicho conde Don Diego Peres tenia, queremos que quede e fynque a nuestra libre dispusyçion. E con esta limitaçion, por la presente mandamos a los del nuestro Consejo y oydores de la nuestra abdiençia e a los alcaldes y jueses de la nuestra casa y chançelleria y de todas las çibdades y villas y lugares de los nuestros reynos y señoríos que agora son o fueren de aqui adelante y a cada uno dellos que lo judguen e manden y pronunçien asy por sus cartas e aquellas lleven e fagan llevar a pura y devida execuçion sy ante ellos sobre la dicha rason fuere tratado pleito o fecho algún pedimiento por qualquiera de las dichas partes. E por mayor fyrmesa, nos desde agora damos y adjudicamos y entregamos y queremos que sean dados e adjudicados y entregados a los dichos condes Don Bemardino y Don Françisco las dichas villas y fortalesas y otros bienes e rentas y todas las otras cosas a cada uno dellos que por la dicha escriptura de pacto y yguala les son adjudicadas para syenpre jamas, e que non sea thenudo de dar cuenta nin rason alguna dello nin de parte dello el uno al otro nin el otro al otro por rason de la dicha subçesion nin a la dicha Doña Mençia por rason de las dichas sus 
arras y dote nin por otro titulo alguno que ellos o qualquier dellos tengan o pretendan aver a los dichos bienes y maguer que las dichas villas y fortalesas y toda la herençia del dicho conde Don Diego Peres o qualquiera parte della demas de las dichas villas de Santa Marta y Palaçuelo pertenescan y puedan pertenesçer en qualquier manera al dicho conde Don Françisco o a la dicha su madre o a qualquier dellos por las dichas cabsas y tytulos o por otras qualesquier, queremos que se guarde y cunpla lo que entre las dichas partes fue y esta asentado y ygualado çerca de la dicha subçesion e herençia, asi por la forma y manera que de suso se contiene, eçebto lo del dicho Adelantamiento Mayor y maravedís de por vida que queden como de suso se contyene. E mandamos a los dichos conde Don Françisco y su madre y a cada uno dellos que tengan y guarden y cunplan lo contenido en la dicha escriptura e cada cosa dello so las penas contenidas en el dicho contrato de transaçion. Asi desto las dichas partes o qualquier délias que fueren nuestra carta o cartas de previlegio mandamos al nuestro escrivano de las confyrmaçiones que las de a cada una de las partes que la pydiere la suya, las quales mandamos al nuestro chançiller y notario y a los otros ofiçiales que están a la tabla de los nuestros sellos que sellen y pasen. Y sy nesçesario es, nos conçedemos y quitamos que aya seydo conçedia(sic) vegnia(sic) de hedad y de tienpo ligytymo a los dichos Condes puesto que esto nin eso en tal hedad en que non pudiesen inpetir nin serles conçedida la dicha venia y interponemos a los dichos patos y transaçiones nuestra real abtoridad e decreto para perpetua validaçion y fyrmesa de los dichos contratos que entre ellos pasaron.

E por quanto vos el dicho conde Don Bemardino fasta aqui fuystes llamado y intitulado de Conde de Santa Marta e agora por rason de la dicha yguala e (fol.2v.) concordia dexastes la villa de Santa Marta al dicho conde Don Françisco el quai se a de llamar y intitular Conde de Santa Marta e suplicastesnos e pidystesnos por merçed que vos diesedes lugar e liçençia para mudar el dicho tytulo y nonbre para que de aqui adelante vos llamasedes y intitulasedes y podays intitular e llamar Conde de la vuestra villa de Ribadavia. Por ende y por vos faser bien e merçed, por la presente vos la otorgamos y conçedemos asi y vos fasemos Conde de la dicha vuestra villa de Ribadavia y vos llamamos Conde de Ribadavia e Adelantado Mayor del dicho Reyno de Gallisia e queremos que asy seays llamado y nonbrado por todos los de nuestros reynos y fuera dellos asi por palabra como por escripvanos publicos o privados o en otra qualquier manera. E que ayades e tengades los privilegios de Conde y Adelantado e gosedes de las prerrogativas y exeçiones y franquisas que los derechos e las leyes de nuestros reynos otorgan e conçeden a los Condes y Adelantados que son fechos e criados por sus reyes e señores naturales, segund que agora vos lo soys. E por la presente suplimos qualesquier defectos, asi de 
justiçia como de solepnidad, que para validaçion perpetua de lo susodicho e de los patos y convenençias y transaçiones es nesçesario y provechoso de se suplir e añadyr por quanto nuestra intençion y determinada voluntad es que todo ello vala y sea fyrme y inviolablemente y syn dyminuiçion alguna. $\mathrm{E}$ sobre esto mandamos que non sea atendida nin esperada otra nuestra carta nin segunda nin terçera juçiones.

E los unos nin los otros non fagades nin fagan ende al por alguna manera so pena de la nuestra merçed y de privaçion de los ofiçios y de confiscaron de los bienes de los que lo contrario fisieren, los quales por la presente aplicamos para la nuestra camara y fisco. E demas mandamos al orne que esta nuestra carta les mostrare que los enplase que parescan ante nos en la nuestra corte doquier que seamos del dia que los enplasare fasta quinse dias primeros siguientes so la dicha pena so la qual mandamos a qualquier escrivano publico que para esto que fuere llamado que de ende al que la mostrare testimonio sygnado con su signo porque nos sepamos en como se cunple nuestro mandado.

Dada en la villa de Madrigal, a dis(sic) e seys dias de abril, año del nasçimiento de Nuestro Señor Ihesuchristo de mili e quatroçientos y setenta y seys años.

Yo el Rey (firma autógrafa). Yo la Reyna (firma autógrafa).

Yo Gaspar de Amon, secretario del Rey e de la Reyna, nuestros señores, y del su Consejo, la fis escribir por su mandado e en las espaldas de la dicha carta estavan escriptos estos nonbres que se siguen: Gaspar dotor. Rodericus dotor.

La qual dicha carta asi presentada ante el dicho bachiller y alcalde susodicho en presençia de mi el dicho Graviel de Valladolid, escrivano, y de los dichos testigos yuso escriptos por el dicho Ferrand Garçia en el dicho nonbre del dicho (fol.3) señor Conde de Ribadavia, dixo al dicho alcalde que por quanto el dicho su parte e el en su nonbre avian menester la dicha carta original para la enviar mostrar y presentar en algunas partes e lugares donde le es conplidero y nesçesario y se themia que si la dicha carta original enbiase mostrar y presentar que se podría perder por fuego o por agua o por furto o por robo o por otra ocasión o caso fortuyto (...) al dicho su parte e el en su nonbre se les podría rescresçer grand daño y interese. Por ende, que pydia e pydio al dicho alcalde que diese liçençia y abtoridad a mi el dicho escrivano publico para que de la dicha carta original escriviese o fisiese escrivir e sacar un traslado o dos o mas, tantos y quantos el dicho Ferrand Garçia en el dicho nonbre del dicho señor Conde $\mathrm{y}$ el dicho señor Conde quisiesen y menester oviesen, a los quales traslados y a cada uno dellos fechos y sacados y signados de mi signo interpusiese su abtoridad y decreto para que valiesen y fisiesen fee en juysio o fuera del doquier que paresçiesen como la dicha carta original paresçiendo. 
E luego, el dicho bachiller y alcalde dixo que oya lo que disia e tomo la dicha carta original en sus manos e católa e miróla e leyóla y diligentemente examinóla y dixo que obedesçia la dicha carta de los dichos Rey e Reyna, nuestros señores, con la mayor reverençia que podia y devia y que la fallava sana e non rota nin rasa nin chançellada nin en parte alguna della sospechosa, mas caresçiente de todo vyçio y sospecha e suspeçion por virtud de lo quai y del dicho pedimiento a el fecho como dicho es, que dava e dio liçençia y abtoridad a mi el dicho escrivano para que de la dicha carta original de los dichos Rey e Reyna, nuestros señores, escriviese y sacase o ñsiese escrevir e sacar un traslado o dos o mas tantos quantos el dicho señor Conde quisiese e el dicho Ferrand Garçia en su nonbre y menester oviesen, a los quales y a cada uno dellos fechos e sacados y del signo de mi el dicho escrivano signados, dixo que interponía e interpuso su decreto e abtoridad para que valiesen y Asiesen fee en juysio y fuera del doquier e ante quien e quandoquier que paresçiesen y cada uno dellos paresçiese bien e conplidamente como la dicha carta original paresçiendo. De lo qual todo en como paso, el dicho Ferrand Garçia en el dicho nonbre del dicho señor Conde pidió a mi el dicho escrivano que gelo diese asi por testimonio signado de mi signo e a los presentes rogaron y rogo que fuesen dello testigos.

Desto son testigos que fueron presentes: Juan Sanches de Arieça y Alonso Garçia de Paredes, escrivanos, y Pedro de Arrióla, procurador, vesinos de la dicha villa de Valladolid, los quales estovieron presentes al dicho pedimiento e abtoridad.

E los que fueron presentes al conçertar y leer este traslado con la dicha carta original onde fue sacado: Alfonso del Castillo, hermano del liçençiado Gonçales de Yllescas, vesinos de la dicha villa de Valladolid, e Gomes de Aranda y Alonso de Contreras, escuderos del dicho liçençiado.

Va escripto entre renglones o dis señores y o dis dicho y sobre raydo o dis por o dis della e dubdoso o dis somos orí e o dis (fol.3v.) alguno e o dis valiese.

E otrosy va escripto entre renglones o dis ora no le enpesca.

E porque yo el dicho Graviel Valladolid, escrivano susodicho, fuy presente a todo lo que dicho es en uno con los dichos testigos y vi la dicha carta original donde por virtud de la dicha liçençia y atoridad a mi dada e otorgada por el dicho bachiller e alcalde a ruego y pedimiento del dicho Ferrand Garçia en el dicho nonbre fielmente escrevi y saque este dicho traslado el qual va escripto en tres fojas deste papel con esta en que va mi signo y por ende fis aqui este mio signo.

En testimonio de verdad, Graviel de Valladolid. (+) 